\title{
UV-reflectivity of parafocal eyespot elements on butterfly wings in normal and abnormal specimens
}

\author{
Mouyu Yang, Ahti Pyörnilä \& V. Benno Meyer-Rochow
}

Yang, M., Pyörnilä, A. \& Meyer-Rochow, V. B. 2004: UV-reflectivity of parafocal eyespot elements on butterfly wings in normal and abnormal specimens. Entomol. Fennica 15: 34-40.

An unusual specimen of Aglais urticae, lacking characteristic UV-reflecting parafocal eyespot elements along the margins of both fore and hind wings, is compared with normal, wild-type specimens. Wing scales, responsible for generating structural coloration, are missing in the abnormal individual and have been replaced with a type that is typical of pigment-based colours. Other modifications seen in the abnormal specimen include firstly, a distal expansion of a uniformly brown region, that otherwise occupies a proximal position on the hind wings of the wild type, and secondly, the lack of a characteristic orange cross-vein band that runs proximal to the parafocal eyespot elements on the hind wing. The differences in coloration between abnormal and wild type are seen as evidence of a proximal-distal developmental axis (originally proposed by Nijhout 1991) and support a view recently aired by Beldade and Brakefield (2003). It is now clear that studies on butterfly eyespot development must consider not only pigmentcontaining scales, but also the structurally modified scales responsible for physical colours, i.e. UV reflectivity.

Mouyu Yang \& V. Benno Meyer-Rochow, Faculty of Engineering \& Sciences, International University Bremen (IUB), P. O. Box 750 561, D-28725 Bremen, Germany

Ahti Pyörnilä, Department of Biology, Oulu University, P.O. Box 3000, SF90014 Oulu, Finland

Received 7 October 2003, accepted 1 December 2003

\section{Introduction}

In recent years the formation of wing eyespots in butterflies has received a considerable amount of attention (Brakefield \& French 1999, Keys et al. 1999, McMillan et al. 2002, Beldade \& Brakefield 2003). Yet, in spite of the many thorough studies on the way eyespots are generated, one aspect appears to have been glossed over: all of the patterns studied lay within the spectral range of human vision, none covered the ultraviolet wavelengths.
Does that matter? We believe it does, since numerous species in New Zealand (MeyerRochow 1991), Asia (Eguchi \& Meyer-Rochow 1983), and Europe (Brunton \& Majerus 1995) possess colour patterns on their wings that are only visible in the UV range and, therefore, interpretations of whether a "colour pattern" is or is not present ought to include also observations in the ultraviolet range of the spectrum. Most insects can perceive UV-A light (wavelength 320-390 $\mathrm{nm}$ ) with their photoreceptors (Briscoe \& Chittka 2001) and at least some butterflies use the UV 
patterns on their wings to communicate with conspecifics (Obara \& Hidaka 1968, Silberglied \& Taylor 1973, Rutowski 1981, Meyer-Rochow 1991, Meyer-Rochow \& Järvilehto 1997).

Moreover, considering that eyespots incorporating yellow, red, or black colours are based on pigments inside the butterfly's scales (Köhler \& Feldotto 1935, Ghiradella 1984), but UV-reflecting patches are the results of physical phenomena depending on structural scale-surface modifications (Lippert \& Gentil 1959, Meyer-Rochow \& Eguchi 1983, Ghiradella 1994, Vukusic et al. 1999), one could question whether the genetic mechanisms, regarded responsible for the generation of eyespots generally (Keys et al. 1999), are indeed also applicable to UV scales.

With the help of a mutant Small Tortoiseshell butterfly (Aglais urticae), lacking UV-reflecting eyespots and exhibiting additional pattern abnormalities, we hope to further stimulate research into these questions of butterfly wing colour development.

\section{Material and methods}

The Small Tortoiseshell nymphalid butterfly Aglais urticae (Fig. 1a) was bred in the field under standard conditions in Oulu (ca. $66^{\circ} \mathrm{N}$ ). Of hundreds of normal specimens examined, one individual caught our attention, because of its unusual coloration (Fig. 1b). The condition must be rare, for an internet request to Lepidopteran societies to inform us of similar sightings remained unanswered. The individual was killed and dried. Colour and UV photographs of this individual were taken and compared with corresponding photographs of specimens with normal coloration. Because UV light consists of radiation of shorter wavelengths, UV photographs tend not to be in focus, as adjustments for distance are made in visible light. The UV-transmission filter had a range of $325-390 \mathrm{~nm}$ and a maximum transmittance $(80 \%)$ to light of $360 \mathrm{~nm}$, coincident with maximum sensitivity of UV-photoreceptor cells in the insect eye (Briscoe \& Chittka 2001). The camera used was a Nikon F2, equipped with a lens that, according to the suppliers, transmitted $50 \%$ of all light of $360 \mathrm{~nm}$ (UV) and $81 \%$ of all light of $380 \mathrm{~nm}$ wavelengths. Since the film used

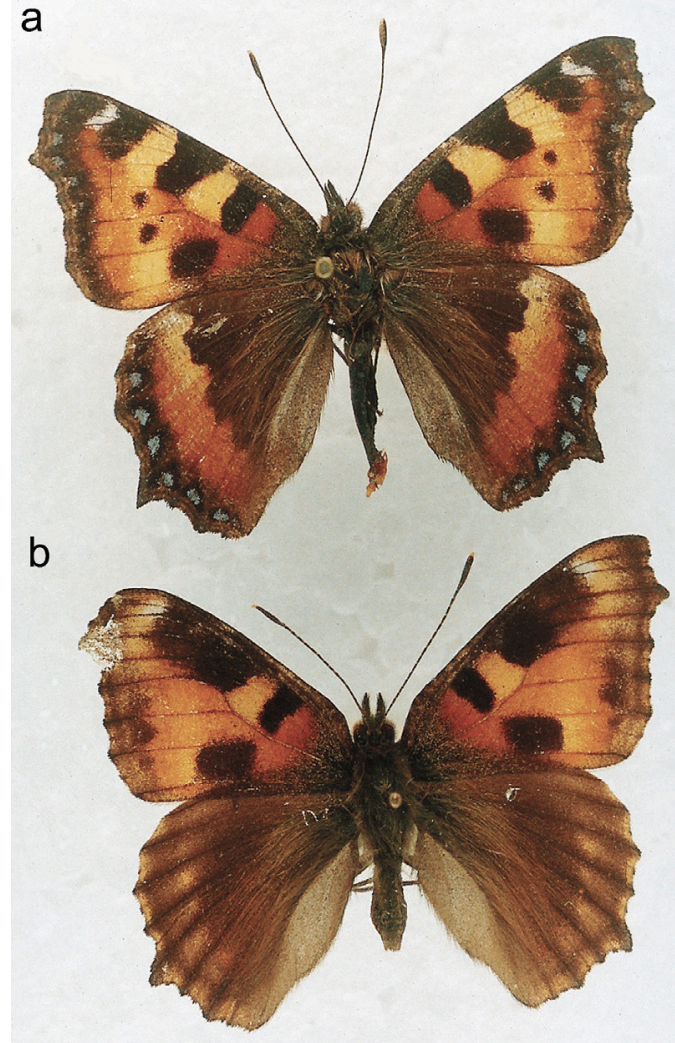

Fig. 1. - a. A normal individual of Aglais urticae, dorsal side. Note bluish eyespots in blackish surroundings along the edges of both fore- and hind-wings and the sharp demarcation border between the reddish-brown band on the hind wing, and the uniformly dark proximal region of the wing. $-b$. The mutant individual, lacking the reddish-brown band of the hind wing (dorsal side). The uniformly dark areas have expanded distally and the eyespots have been replaced by patches of the reddish-brown band that also seems to have shifted distally. The blackish surroundings of the eyespots are completely missing, and bluish coloration is absent. The original photographs are in colour.

(=Kodak TRI-X) was sensitive to wavelengths ranging from $300 \mathrm{~nm}$ wavelength to the near infra-red, our UV photographs were obtained with bright sunlight of 350-390 nm wavelengths.

Preparation for scanning electron microscopy was standard and involved one millimetre square samples of UV-reflecting and UV-absorbing wing regions. The chosen pieces, some of which dorsal, some of which ventral side up, were stuck on regular SEM-aluminium stubs, coated under vacuum with $60 / 40$ gold/palladium to a thickness 

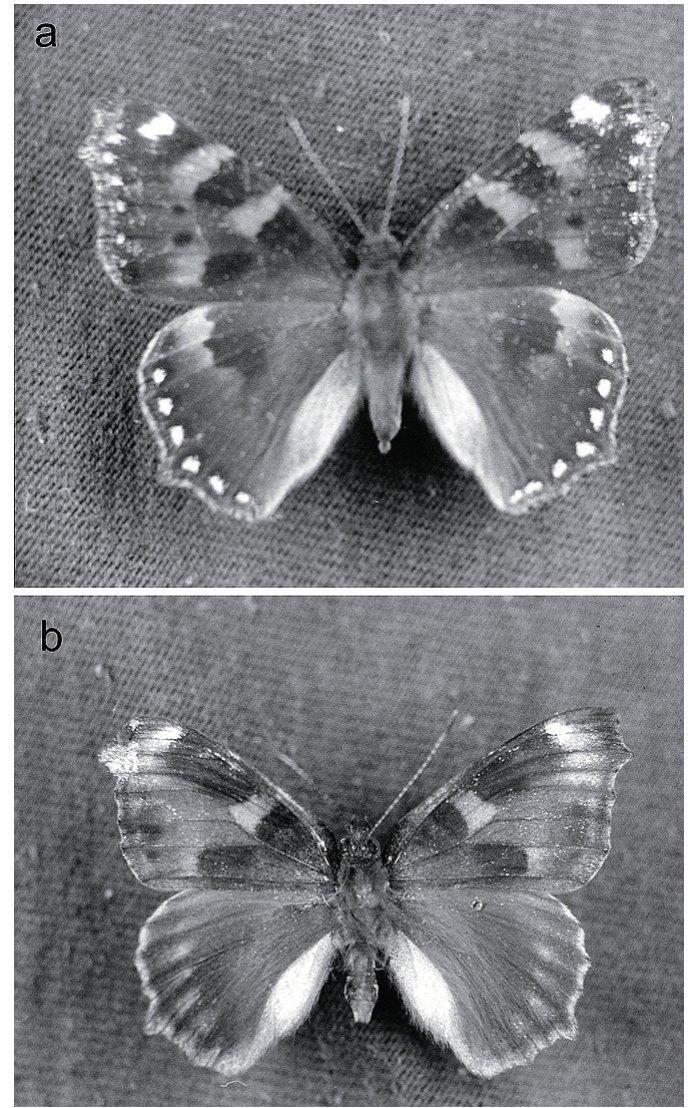

Fig. 2. - a. UV photograph of normal A. urticae individual, demonstrating high reflectivity of eyespots, especially on the hind wings. Note the border between the uniformly-coloured wing region and the reddishbrown band. - b. UV photograph of the mutant $A$. urticae, showing absence of eyespot UV reflectivity and a distal expansion of UV absorbing uniformly-coloured wing areas.

of 200 Ångström, and observed under a Jeol JSM-6300F scanning electron microscope, operated at $6 \mathrm{kV}$.

\section{Results}

Normal individuals of $A$. urticae are seen by a human observer as shown in Fig. 1a. A number of small and faintly blue parafocal eyespots, surrounded by blackish scales, are visible along the margins of both front and hind wings. On the hindwing there is a sharp colour transition from a uniformly dark posterior region to a more dis- tally-placed band of orange-brown coloration. Under UV illumination the blue scales of the parafocal eyespot elements become greatly more visible as they are strongly reflecting the shorter wavelengths (Fig. 2a), while the hindwing demarcation line between the more proximal dark region and the lighter distal band appears more or less unchanged in appearance.

The abnormal individual, as seen by a human observer (Fig. 1b), possesses lighter, yellowishbrown spots in places of the bluish eyespots, and lacks the clear border between the darkly coloured proximal wing region and the orangebrown cross-vein band so obvious in the normal indivdiduals. In fact, the characteristic hind wing band is absent and only remnants of it can be seen in places where the bluish eyespots used to be. The blackish scales appear to have altogether disappeared from the hindwing, but interestingly, the two black spots (probably true homologues of eyespots) in the centre of the forewing have also moved distally, but the more proximal black bands have remained in the same place. The examination of the UV photograph of the abnormal specimen (Fig. 2b) demonstrates that there is no UV reflectivity in the region of the parafocal eyespot elements. This suggests that the lack of eyespot UV reflectivity appears to have been coupled with a distal expansion of the uniformly dark hind wing region and a replacement of the UV-reflecting parafocal eyespot scales with pigmentcontaining scales.

To verify this notion, we examined scales from the eyespot region of the aberrant individual (Fig. 3a) and a normal specimen (Fig. 3b). The spacing of the longitudinal ribs was more or less the same in both individuals, but regarding crossrib morphologies the two individuals were very different. Wide spaces, allowing light to enter the scale, were developed between the cross ribs of the mutant. Such scales are typical of those involved in generating pigment-based wing coloration. However, the presence of narrowly-spaced microridges, commonly associated with physical colours (Allyn \& Downey 1977), was apparent in the scales from the UV-reflecting region of the normal individual. This seems to confirm that scale modifications in the mutant $A$. urticae had occurred in places where UV reflectivity should have taken place normally, although scales of dif- 

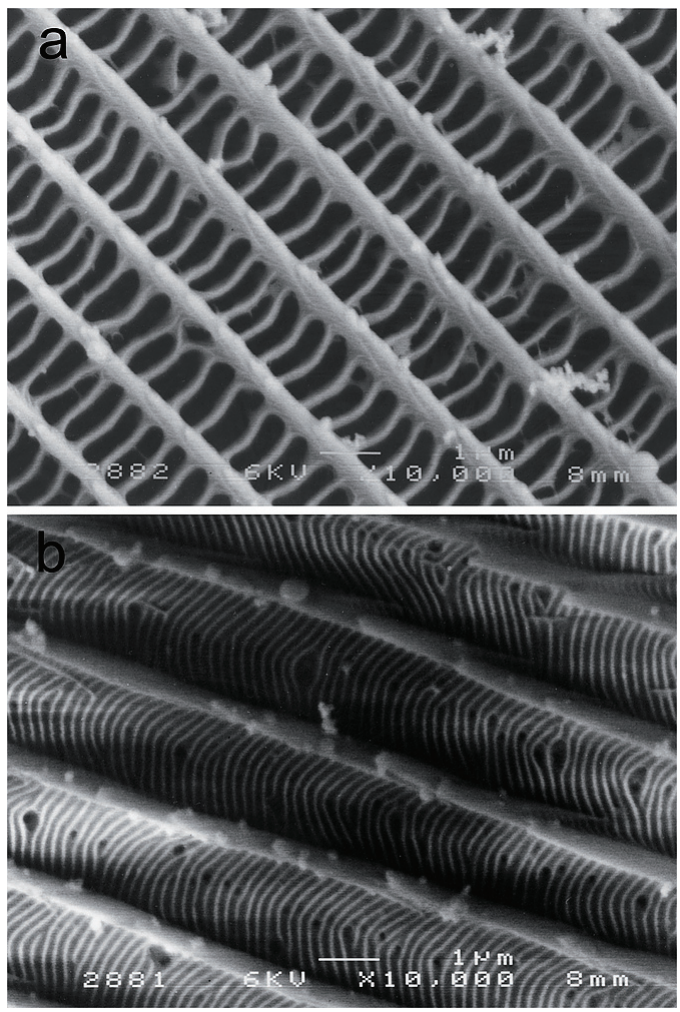

Fig. 3. - a. Scanning electron micrograph of scale detail from eyespot region in the mutant $A$. urticae, showing ladder-like arrangement with vast gaps between cross ribs, characteristic of pigment containing scales. Only faint traces of microridges superimposed on the longitudinal ribs are visible. The scale bar 1 $\mu \mathrm{m}$. $-\mathrm{b}$. Scanning electron micrograph of scale detail from the eyespot region of a normal individual, showing a pattern of densely-spaced narrow microridges developed between adjacent longitudinal ribs, characteristic of scales that are involved in UV-reflectivity on the basis of structural features. The scale bar $1 \mu \mathrm{m}$.

ferent pigment-based colour can resemble those typical of the UV-reflecting wing areas (Janssen et al. 2001) and UV-reflectivity can be a consequence of pigmentation (Makino et al. 1952).

\section{Discussion}

Butterfly eyespots are considered serially homologous pattern elements (Monteiro et al. 2003), probably derived through complex gene regulating cascades. Galant et al. (1998) had earlier demonstrated that initial cellular and molecular processes in the formation of both neural and scale precursor cells were similar and that the spatial regulation of an AS-C gene was modified during Lepidopteran evolution. A distinction between different colour scales, however, was not made at that time. The question of how different genes are being expressed in association with different colour scales was investigated by Brunetti et al. (2001) and it seems that signalling from the focus of an eye spot induces the expression of regulator genes that subsequently control the final colour patterns of the rings around the eyespot. To what extent that also applies to structurally-produced and not pigment-based colours was not explicitly studied, but one can probably assume that for the UV scales similar control mechanisms are in place. With the help of X-rayinduced mutants for eyespots in the nymphalid Bicyclus anynana, Monteiro et al (2003) were able to suggest that so-called 'focus regulatory genes' are turned on in each wing cell "via the input of regional regulatory genes that bind to discrete modules on their cis-regulatory domains". Their work focused on visible colour patterns and eyespots and was, thus, concerned with wing scales containing different pigments, but not necessarily differing morphologically.

In a separate paper it was suggested that all eyespots in a butterfly were "genetically integrated" and that there were correlations among different wing traits, all focusing on the same type of pattern element, viz. the eye-spot (Beldade \& Brakefield 2003). This is a departure from the earlier view that the pattern in its entirety, and not just separate or isolated eyespots, ought to be considered "a single character" (Brakefield 2001). Apparently single gene mutants in $B$. anynana can cause large pattern changes in overall eyespot size, shape, and number as well as colour composition, but have "no effect on the other pattern elements" (McMillan et al. 2002). This statement is clearly at variance with our specimen, in which lack of UV reflectivity of hind wing eyespots was combined with effects on other wing pattern elements, namely the crossvein colour demarcation bands in the hind but not fore wings. In fact, Beldade et al. (2002 a, b) have shown that even with serially-repeated elements such as eyespots, there is genetic variation enabling developmental and evolutionary flexibil- 
ity for changes in individual elements.

Nijhout (1991) originally dscribed a system of homologies, termed the "nymphalid ground plan", that linked all colour pattern elements with the proximal/distal axis of the wing. What is dominating recent research, however, is the focus on the anterior/posterior axis and the formation of many eyespots as the consequence of an anterior/posterior compartmentalization of sequential gene expression. In our abnormal specimen, the lack of UV-reflecting marginal eyespots is combined with an absence of the hindwing colour demarcation line (so prominent in normal individuals) and a shift to a more distal location of the orange-yellow band. Lack of UV reflectivity, thus, appears to have resulted not actually in reduced numbers of parafocal eyespots or in a positional change of the eyespots, but in a pattern shift from proximal (= mid-wing) to distal (= wing margin). How this finding would be compatible with the view of an anterior/posterior eyespot generation remains to be seen.

What could have caused the pattern change in our specimen? Was it a genetic mutation or did it represent a morphological phenotype, caused by extreme environmental conditions during rearing? Seasonal polyphenism with regard to eyespot sizes and numbers is, after all, known to occur in a variety of butterfly species. It can be traced to certain environmental variables, e.g. dry/wet conditions and low/high temperatures (Nijhout 1991, Brakefield \& French 1999). Moreover, in the swallowtail butterfly Papilio xuthus, high titers of ecdysteroids shortly after pupation apparently lead to increased ventral eyespot sizes, while hypodermal injections of molsin, an enzyme of Aspergillus saitoi, which liberates tyrosine and phenylalanine, into 0-2 day old pupae, also causes pattern perturbations, but chiefly in regard to (visible, i.e. pigment-based) coloration (Umebachi \& Osanai 2003).

Since our aberrant specimen was bred together with other perfectly normal ones under identical conditions, we rule out the possibility of polyphenism, but cannot exclude the possibility that the one abnormal individual stemmed from a pupa that had been frost-damaged ( $c f$. illustrations 9 and 10 on Plate IV in Anonymous [1910]). Obviously, the best evidence of whether the abnormal pattern in our interesting phenotype was genetically-determined, as opposed to environmentally-induced, would have come from the progeny of the abnormal individual. Alas, the specimen was preserved before it had a chance to breed. However, frost forms, lacking hindwing parafocal eyespots, may mate with normal individuals, but according to experiments carried out by Max Standfuss (cited without proper reference in Anonymous [1910]), the offspring apparently resemble the frost form and not normal individuals. We simply do not know whether the abnormal specimen was indeed a genetic mutant, perhaps caused by frost, or whether other mutagens were involved in giving rise to the abnormal coloration. All we can state for certain is that none of the experimentally-generated mutants or phenotypes examined by Brakefield et al. (1998) or Brakefield and French (1999) show eyespot changes in combination with wing-band alterations that resemble those we reported in this paper.

Our specimen, completely lacking the UV-reflecting parafocal eyespot elements and exhibiting changes in other pattern elements, shows that there is a link between proximal and distal wing coloration (very obvious with regard to the hindwing, but not so with regard to the forewing) and that, at least in our A. urticae, the pattern in its entirety is not a "single character" produced along the anterior/posterior axis. Consequently, it would seem that in the evolution of parafocal eyespots on butterfly wings proximal/distal gene expressions not only occur, but can be uncoupled from anterior/posterior associations.

Since our results depended to a considerable extent on the visualisation of eyespots containing or not containing UV-reflecting scales, we feel that our recommendation to routinely use UV photography in researches on butterfly colour patterns is vindicated. The functional anatomy of the eye of $A$. urticae, incidentally, has been beautifully studied by Kolb (1985), who also presented evidence for UV-sensitivity in that species.

Acknowledgements. VBM-R thanks Prof. M. Järvilehto and the Academy of Finland for supporting his initial work in Finland through a visiting professorship in the University of Oulu. MY thanks the International University Bremen for financial support. The authors would like to acknowledge Dr. J. Itämies of the Zoological Museum of 
Oulu, the staff of the Electron Microscopy Unit of the University of Oulu, and Dr. Doekele Stavenga of the University of Groningen for providing the necessary "push" to complete the study.

\section{References}

Allyn, A. C. \& Downey, J. C. 1977: Observations on male UV reflectance and scale ultrastructure in Phoebis (Pieridae). - Bulletin of the Allyn Museum 42: 1-20.

Anonymous 1910: Schmetterlinge. - In: Meyers Grosses Konversations-Lexikon, $6^{\text {th }}$ edition, vol. 21: 803-807. Leipzig \& Wien.

Beldade, P. \& Brakefield, P. M. 2003: Concerted evolution and developmental integration in modular butterfly wing patterns. - Evolution and Development 5: 169179.

Beldade, P., Brakefield, P. M. \& Long, A. D. 2002a: Contribution of distal-less to quantitative variation in butterfly eyespots. - Nature 415: 315-318.

Beldade, P., Koops, K. \& Brakefield, P. M. 2002b: Modularity, individuality, and evo-devo in butterfly wings. - Proceedings of the National Academy of Sciences (U. S. A.) 99: 14262-14267.

Brakefield, P. M. 2001: Structure of a character and the evolution of butterfly eyespot patterns. - Journal of Experimental Zoology 291: 93-104.

Brakefield, P. M. \& French, V. 1999: Butterfly wings: the evolution of development of colour patterns. - Bioessays 21: 391-401.

Brakefield, P. M., Kesbeke, F. \& Koch, P. B. 1998: The regulation of phenotypic plasticity of eyespots in the butterfly Bicyclus anynana. - The American Naturalist 152: 853-860.

Briscoe, A. \& Chittka, L. 2001: The evolution of color vision in insects. - Annual Review of Entomology 46: 471-510.

Brunetti, C. R., Selegue, J. E., Monteiro, A., French, V., Brakefield, P. M. \& Carroll, S. B. 2001: The generation and diversification of butterfly eyespot color patterns. Current Biology 16: 1578-1585.

Brunton, C. A. \& Majerus, M. E. N. 1995: Ultraviolet colours in butterflies: intra- or inter-specific communication? - Proceedings of the Royal Society of London, ser. B 260: 199-204.

Eguchi, E. \& Meyer-Rochow, V. B. 1983: Ultraviolet photography of fortythree species of Lepidoptera, representing ten families. - Annotationes Zoologiae Japonensis 56: 10-18.

Galant, R., Skeath, J. B., Paddock, S., Lewis, D. L. \& Carroll, S. B. 1998: Expression pattern of a butterfly achaete-scute homolog reveals the homology of butterfly wing scales and insect sensory bristles. - Current Biology 8: 807-813.

Ghiradella, H. 1984: Structure of iridescent lepidopteran scales: variations on several themes. - Annals of the Entomological Society of the United States of America 77: 637-645.
Ghiradella, H. 1994: Structure of butterfly scales: patterning in an insect cuticle. - Microscopy, Research, and Technique 27: 429-438.

Janssen, J. M., Monteiro, A. \& Brakefield, P. M. 2001: Correlations between scale structure and pigmentation in butterfly wings. - Evolution and Development 3: 415-423.

Keys, D. N., Lewis, D. L., Selegue, J. E., Pearson, B., Goodrici, L. V., Johnson, R. L., Gates, J., Scott, M. P. \& Carroll, S. B. 1999: Recruitment of a hedgehog regulatory circuit in butterfly eyespot evolution. - Science 283: 532-534.

Köhler, W. \& Feldotto, W. 1935: Morphologische und experimentelle Untersuchungen über Farbe, Form und Struktur der Schuppen von Vanessa urticae und ihre gegenseitigen Beziehungen. - Wilhelm Roux Archiv für Entwicklungsmechanik der Organismen 136: 313399.

Kolb, G. 1985: Ultrastructure and adaptation in the retina of Aglais urticae (Lepidoptera). — Zoomorphology 105: 90-98.

Lippert, W. \& Gentil K. 1959: Über lamellare Feinstrukturen bei den Schillerschuppen der Schmetterlinge vom Urania- und Morpho-Typ. - Zeitschrift für Morphologie und Ökologie der Tiere 48: 115-122.

Makino, K., Satoh, K., Koike, M. \& Neno, N. 1952: Sex in Pieris rapae $\mathrm{L}$. and the pteridine content of their wings. - Nature 170: 933-934.

McMillan, O.W., Monteiro, A. \& Kapan, D.D. 2002: Development and evolution on the wing. - Trends in Ecology and Evolution 17: 125-131.

Meyer-Rochow, V. B.\& Eguchi, E. 1983: "Flügelfarben, wie sie die Falter sehen" - a study of UV and other colour patterns in Lepidoptera. - Annotationes Zoologicae Japonensis 56: 85-99.

Meyer-Rochow, V. B. \& Järvilehto, M. 1997: Ultraviolet colours in Pieris napi from northern and southern Finland: arctic females are the brightest! - Naturwissenschaften 84: 165-168.

Meyer-Rochow, V. B. 1991: Differences in ultraviolet wing patterns in the New Zealand lycaenid butterflies Lycaena salustius, L. rauparaha, and L. feredayi as a likely isolating mechanism. - Journal of the Royal Society of New Zealand 21: 169-177.

Monteiro, A., Prijs. J., Bax, M., Hakkaart, T. \& Brakefield, .PM. 2003: Mutants highlight the modular control of butterfly eyespot patterns. - Evolution and Development 5: 180-187.

Nijhout, H. F. 1991: The development and evolution of butterfly wing patterns. - Smithsonian Institution Press, Washington DC.

Obara, Y. \& Hidaka, T. 1968: Recognition of the female by the male on the basis of ultraviolet reflection in the white cabbage butterfly Pieris rapae crucivora Boisduval. - Proceedings of the Japanese Academy 44: 829-832.

Rutowski, R.L. 1981: Sexual discrimination using visual cues in the checkered white butterfly (Pieris protodice). - Zeitschrift für Tierpsychologie 55: 325-334. 
Silberglied, R.E. \& Taylor, O.R. 1973: Ultraviolet differences between the sulphur butterflies Colias erytheme and $C$. philodice and a possible isolating mechanism. — Nature (London) 242: 406-408.

Umebachi, Y. \& Osanai, M. 2003: Perturbation of the wing color pattern of a swallowtail butterfly, Papilio xuthus, induced by acid carboxypeptidase. - Zoological Science 20: 325-331.

Vukusic, P., Sambles, J. R., Lawrence, C. R. \& Wootton, R. J. 1999: Quantified interference and diffraction in single Morpho butterfly scales. - Proceedings of the Royal Society of London, ser. B 266: 1403-1411. 